\title{
Referrals to a pediatric emergency room of a tertiary care teaching hospital before and after introduction of a referral education module- a qualitative study
}

\section{Gopalakrishnan Ezhumalai}

Post Graduate Institute of Medical Education and Research https://orcid.org/0000-0003-2629-6893 Jayashree Muralidharan ( $\square$ mjshree@hotmail.com )

https://orcid.org/0000-0002-6149-1355

Arun Bansal

Post Graduate Institute of Medical Education and Research

Karthi Nallasamy

Post Graduate Institute of Medical Education and Research

Bhavneet Bharti

Post Graduate Institute of Medical Education and Research

Research article

Keywords: Quality of referral, Pediatric emergency, Triage

Posted Date: January 6th, 2020

DOI: https://doi.org/10.21203/rs.2.20001/v1

License: (c) (1) This work is licensed under a Creative Commons Attribution 4.0 International License.

Read Full License 


\section{Abstract}

Background: Provision of timely care to critically ill children is essential for good outcome. With development of specialized pediatric critical care units, referral from community and smaller peripheral hospitals has received greater impetus. Our tertiary care hospital caters to referrals from a wide geographical area. Since there is no standard referral and feedback system in India, we decided to evaluate the quality of referrals coming to our Emergency Room (ER) with respect to their demography, association with severity of illness and mortality. We plan to use this data to establish a standard referral and feedback process to streamline our ER referrals.

Methods: Our study was completed in three phases in Pediatric ER;Pre-intervention, Intervention and Post intervention phases. Quality of referrals was graded by granting one score to presence of each item when matched with a quality checklist performa. A referral was graded 'good', 'fair' and 'poor' if it scored >7, 5 7 and $<5$ points respectively. Case studies, expert opinions, and lacunae observed in first phase were taken into consideration while preparing the referral education module, that was administered to health care providers of referring hospitals. Quality of referrals was compared between pre and post intervention phases.

Results: Majority of inpatient admissions were 'referred' patients (99.3\%). Most referrals belonged to the neighboring states of Punjab (48.2\%) and Haryana (22.4\%). Major referrals were from public sector hospitals $(80.9 \%)$ of which the teaching hospitals topped the list (53.6\%). Most common mode of transport was government run ambulance services(85.5\%) and the common reason for referral was need for PICU bed and/or mechanical ventilation (50.4\%). The post intervention phase saw a significant decline in the proportion of poor referrals (93.2 vs.78.2\%; $p=0.001)$ and a significant increase in the proportion of fair $(6.1$ vs $18 \% ; p=0.001)$ and good referrals $(0.7$ vs $18 \% ; p=0.001)$ Proportion of children presenting to triage with physiological decompensation with respect to poor referrals had significantly decreased in post intervention phase [580(79.8\%) vs 1025(93.7\%); $p=0.0001]$.

Conclusion:Referral education had significantly improved the quality of referrals coming to our ER. Continuing education will be required for sustained and increased benefits.

Key words: Quality of referral, Pediatric emergency, Triage

\section{Background}

Provision of optimal and timely care to critically ill children is crucial for best outcome. With development of specialized pediatric critical care units, referral from community, district or other peripheral heath care facilities has gained greater momentum(1). Referral is a process in continuum; beginning from the referring and ending at the referred facility(2). Maintenance of optimal physiology during referral is vital $(3,4)$.India lacks an organized referral network. This is further compounded by multiple barriers which include poor pre-referral communication and transport facilities(5). The Emergency Room (ER) at the Advanced Pediatrics Centre is a standalone unit that caters to patients referred from 5 neighboring states 
viz Punjab, Haryana, Himachal Pradesh, Rajasthan and Uttar Pradesh. It sees about 18,000 to 20,000 admissions per year, of which more than three fourths are referred patients both from public (community health centers, district hospitals, and medical colleges) and corporate sector hospitals of the above states. Since there is no standard referral and feedback system in India, we decided to conduct this study to ascertain the quality of referrals coming to our Emergency Room and their association with severity of illness and mortality before and after introduction of a referral education module. Using this data, we plan to establish a standard referral and feedback process that will help streamline our emergency referrals.

\section{Methods}

We conducted a prospective before and after study which was divided into three phases; Pre- intervention (Phase-I), Intervention (Phase II) and Post intervention (Phase III). All consecutive children aged $>1$ month to 12 years of age referred to our Emergency Room were included in the study.

The pre- intervention phase lasted for 4 months from January 2016 to April 2016. During this phase a total 1403 children referred from different hospitals were enrolled. The referral letters accompanying these patients were collected and studied for quality and completeness by comparing them with a quality checklist performa. This comparator checklist was made a priori based on WHO

recommendations(6).The quality of each referral was estimated by granting one score to the presence of each item in the performa. Some items were subdivided into their integral components and each component was granted equal scores between 0.2 or 0.5 in accordance with the number of components. All the components included were given equal importance. Each referral letter was given an objective score and graded as 'good' if it scored > 7 points, 'fair' if it scored between 5-7 and 'poor' if the score was less than 5 .

In Phase-II (May to August 2016) we developed a referral education module with inputs from emergency and social pediatric experts $(\mathrm{JM}, \mathrm{AB}, \mathrm{BB})$. The lacunae in referrals observed during the first phase were analyzed and discussed and steps to prevent them were included in the module. Anonymized case studies in which identity of patient, referring hospital and physician were kept confidential, were prepared to highlight both good referrals and common errors during referrals. The content of the module emphasized on 1) How to identify a sick child who needs referral 2) importance of timely referral,3) key components to be addressed during the referral process like stabilization, and maintenance of airway, breathing and circulation, fluids and medications 4) Importance of good pre-referral communication, 5) Importance of good written documentation, and feedback. This module was peer reviewed by all the coinvestigators before finalizing it. The final module (duration 2 hours) was then administered onsite to all the doctors, and nurses working in the emergency area of various hospitals from where the maximum referrals had taken place in Phase I. The list of hospitals to be visited was prepared and the concerned hospitals were informed at least 1 week prior to the scheduled visit to ensure maximum participation from concerned health care providers of that site. On the proposed date and time, the team of investigators visited the site and administered the module to the target group. Written handouts 
emphasizing key aspects of a good referral, were also given. Small group discussion addressing their barriers and problems were also conducted.

In the post intervention phase, which lasted for 5 months from September 2016 to January 2017, a total 957 referred cases were enrolled. The referral letters and their quality were assessed once again with the same quality checklist performa and objectively scored as described for Phase I.

The pre and post intervention phase were then compared with respect to demography of referral, association with severity of illness and mortality using Chi-square test or Student's t test as applicable. Quality of referral is expressed as proportion. The association between quality of referral and the physiological status at triage was also determined using Chi-square test. $\mathrm{P}<0.05$ was taken as significant.

\section{Outcome parameters}

Change in proportion of good, fair and poor-quality referrals before and after the referral education module was taken as primary outcome. Reasons for referral, proportion of patients transported in ambulance with a trained emergency personnel, association between the quality of referral and triage physiological status were secondary outcome parameters.

\section{Results}

A total of 1403 and 957 referrals were studied during the pre-intervention and post intervention phases respectively. Major share of referrals in both phases were from the States of Punjab $[(n=695 ; 49.5 \%)$ vs $(n=450,47 \%)]$ followed by Haryana $[(n=313,22.3 \%)$,vs $(n=194,20.3 \%)]$, within Chandigarh $[(n=190$, $13.5 \%)$,vs $(n=154,16.1 \%)]$,Himachal Pradesh $[(n=147,10.4 \%)$,vs $(n=91,9.4 \%)]$ and Uttar Pradesh[ $(n=$ $58,4.1 \%)$ vs $(n=68,7.1 \%)]$. The type of healthcare facility referring to our center in both the phases are shown in Table 1. Most referrals came from public sector hospitals with a small proportion coming from corporate hospitals. Government run ambulance services was the most common mode of transport availed in both phases [pre intervention 1200 (85.5\%) vs post intervention 820(85.7\%)], followed by private ambulance services [pre intervention $147(10.5 \%)$ vs post intervention $95(9.9 \%)$ ] and self-owned four wheeler [pre-intervention $56(4 \%)$ vs post intervention $42(4.4 \%)]$. However, only 7 to 8 referrals in both phases had a health care personnel accompanying the patients to the referred facility. 
Table 1

Type of Referring Health care Facilities

\begin{tabular}{|lll|}
\hline Public Sector & Preintervention & Postintervention \\
\hline Medical College \& Teaching Hospital & $664(47.3 \%)$ & $397(41.4 \%)$ \\
\hline Community Health Care Centers & $317(22.5 \%)$ & $205(21.4 \%)$ \\
\hline District Hospitals & $217(15.4 \%)$ & $197(20.5 \%)$ \\
\hline Corporate Sector & Preintervention & Postintervention \\
\hline Private Hospitals & $186(13.2 \%)$ & $147(15.3 \%)$ \\
\hline Medical College \& Teaching Hospitals & $19(0.01 \%)$ & $11(0.01 \%)$ \\
\hline
\end{tabular}

Indications for referral

Half of the patient referrals were for higher level of pediatric intensive care $(n=482,50.4 \%)$ of which about $40 \%(n=195)$ required mechanical ventilation. The other indications were: need for expert diagnostic opinion $(n=343,35.8 \%)$, financial constraints $(n=101,10.6 \%)$ and parental request $(n=31$, $3.2 \%)$.

Quality of referrals:

Majority of the referrals in the pre-intervention phase were poor $(n=1308,93.2 \%)$; only $10(0.7 \%)$ referrals were graded as good. Most referrals [1328(94.7\%)] had inadequate information related to pre-referral hemodynamic, respiratory and neurological stabilization, clinical findings, investigations, diagnosis, and treatment received at referring facility and during transport. Only a small proportion $(3.7 \% ; n=52)$ had appropriate pre-referral documentation. There was no pre-referral communication with the referred facility, as well as no communication with parents/ guardians regarding risk of transport. In the post intervention phase, the proportion of bad referrals had significantly decreased (pre-intervention $93.2 \%$ vs. post intervention $78.2 \% ; p=0.001$ ) and the good and fair referrals had significantly increased [pre-intervention $0.7 \%$ vs. post intervention $4 \% ; p=0.001$ and $6.1 \%$ Vs $18 \% ; p=0.001$ respectively]. Pre-referral documentation although inadequate had significantly improved in the post intervention phase ( $3.7 \% \mathrm{vs}$. $24 \% ; p=0.001$ ); documentation regarding hemodynamic, respiratory, neurological stabilization prior to referral and treatment during transport was significantly better in the post intervention phase ( $0 \mathrm{vs} .16 \%$; $p=0.0001)$. However, pre-referral communication, with parents regarding risk of transport remained similar in both the phases. The comparative data on quality of referrals in both the phases is as depicted in the (Fig. 1). The quality of referrals had a significant association with the physiological status at the time of triage in ER. Proportion of children presenting to triage with physiological decompensation with respect to poor referrals had significantly decreased in post intervention phase [580(79.8\%)] as compared to the pre-intervention phase $[1025(93.7 \%)](p=0.0001)$. 


\section{Discussion}

This study was designed firstly to observe the quality of referrals coming to a pediatric Emergency Room of a tertiary care multispecialty teaching hospital and secondly to develop a referral education module for health care providers at different referring healthcare facilities; and thirdly to assess the difference in the quality of referrals between both the phases.

A total of 12,490 patients visited our ER during the pre and post intervention phases combined. Majority were 'referred' patients, primarily from public sector teaching hospitals. Furthermore, most referred patients required admission. A study from another teaching and tertiary hospital has reported findings to the contrary; only $22.5 \%$ of referred patients required admission(7). The higher admission rate of referred patients in our set up is probably related to multiple factors. Ours is the only tertiary level super-specialty public sector hospital catering to 5 neighboring states. Lack of organized emergency and intensive care services and expertise in the peripheral hospitals, causes our hospital to bear the brunt of large number of referrals and admissions.

Accurate transfer of patient information in the form of a well-documented referral letter is crucial for maintaining continuity of care especially in sick children. Lack of vital information with respect to clinical examination findings and treatment received, poses lot of problems for the referred facility. Since most patients in our set up are also ignorant about the treatment given, the healthcare providers at the receiving facility are highly dependent on the referring doctors documentation or verbal information. We found that almost all referral letters lacked the most essential information required for maintaining continuity of care. The referral letters in the pre-intervention phase had missing information related to illness, clinical examination, treatment given, investigations, procedures and pre-referral stabilization. Studies have shown that nearly one third of specialist referrals from general practitioner (GP) lack essential clinical information and are often inadequate(8-10).Similarly another study evaluating the quality of GP referrals to a South African tertiary care hospital, reported that certain important components related to pre referral treatment $(6.3 \%)$, laboratory tests $(8.3 \%)$ and special tests $(4 \%)$ were mentioned in very few referral letters only(11).

On the other hand, nearly half of the referral letters in both phases contained reasons for referral. Though much lower than that reported by Langalibaele et al (11) and Leonard et al(12) which was $88 \%$ and $100 \%$ respectively. Although indications were mentioned, pre-referral communication with the referred center was absent. In a resource limited setting like ours, absence of prior information results in poor preparedness at the tertiary level, the case in example being need of a ventilator.

We observed that all the referral letters were hand written and unstructured. Majority of the referral letters were in the 'letter format' similar to that reported by Xiang et al (13). Lack of structured format could have been one of the reasons for the poor quality and deficiency of several domains in these referral letters similar to that reported by Manis et al $(14,15)$. A structured format is preferable as it ensures completeness of information by forcing the health care provider to fill all the columns and check all the required boxes. 
Various methods have been tried worldwide to improve the incorporation of relevant information in referral letters. Referral guidelines, structured performa, peer or specialist feedback, risk factor checklist, referral management scheme (RMS), have been some of the measures tried to improve referral content (10). In the index study introduction of a referral education module did make a significant impact. The proportion of poor referrals had significantly reduced along with a corresponding significant increase in proportion of fair and good referrals. Referral content with respect to clinical examination findings, and pre-referral and during transport treatment details had improved significantly. The proportion of patients received in a physiologically decompensated state had significantly decreased in the post intervention period. Although we cannot definitively conclude on the causality, our findings suggest that our module had helped sensitize the healthcare providers in peripheral healthcare facilities about the need for timely stabilization, and good quality referral. It has enhanced communication between the referring centers and our facility and strengthened the back-referral process i.e. sending back stabilized patients to the primary referring facility.

This study paves the way for development of an organized referral network which connects tertiary care facilities with the other public and corporate hospitals in the periphery. The initial sensitization achieved by our study should be further consolidated by a more sustained multifaceted outreach and continuous feedback process. These interventions will also help reduce the unnecessary referrals and consequent overcrowding of a tertiary care facility. The major limitation of our study was that we could not cover all the health care facilities that were referring to us as they were distributed over a widely geographical area. We had targeted our interventions on hospitals from where maximum referrals were received during the pre-intervention phase. Secondly this being a before and after study design, there could have been Hawthorne effect in the post intervention phase.

\section{Conclusion}

Referral education of healthcare providers had improved the quality of referral by improving some domains of referral content. Proportion of children presenting to triage with physiological decompensation had significantly decreased after introduction of this module. This change suggests sensitization of the peripheral hospitals towards a better referral process. Continued multifaceted approach will be required for sustained and increased benefits. This will pave the way for building an organized referral and back referral network among the healthcare facilities in this particular geographic region and thus help reduce the overburdening of tertiary care facilities.

\section{Abbreviations}

ER

Emergency Room

ED

Emergency Department

WHO 
World Health Organization

GP

General Practitioner

$\mathrm{IMCl}$

Integrated Management of Childhood Illness

UK

United Kingdom

RMS

Referral Management scheme

SD

Standard Deviation

PICU

Pediatric Intensive Care Unit

NICU

Neonatal Intensive Care Unit

AllMS

All India Institute of Medical Sciences

PGIMER

Post Graduate Institute of Medical Education and Research

\section{Declarations}

Ethics approval and consent to participate- Ethics approval was taken from the Ethics Committee of Post Graduate Institute of Medical Education and Research, Chandigarh,India

Reference Number: NK/2512/MD/799-800; Dated 27.01.2016

Consent for publication- Departmental Consent for publication was taken (Reference Number: DRB-10619; dated 04.06.2019

No written consent was taken from the parent or the referring health care facilities during the first phase, since only referral letters accompanying the patient and other records were studied in details. However verbal consent was taken during second and third phase of study from the healthcare providers of referring facilities

Availability of data and material- Not provided

Competing interests- None

Funding- None

Authors' contributions: Table attached 


\begin{tabular}{|c|c|c|c|}
\hline $\begin{array}{l}\text { Author } \\
\text { order }\end{array}$ & $\begin{array}{l}\text { Author } \\
\text { Name }\end{array}$ & Authorship & $\begin{array}{l}\text { Affiliation (Department, Institution, City, State, } \\
\text { Country) }\end{array}$ \\
\hline \multirow[t]{2}{*}{1} & \multirow[t]{2}{*}{ GE } & Principle investigator & \multirow{2}{*}{$\begin{array}{l}\text { Department of Pediatrics, Advanced Pediatrics } \\
\text { Centre, Post Graduate Institute of Medical } \\
\text { Education and Research (PGIMER), Chandigarh, } \\
\text { India - } 160012 \text {. }\end{array}$} \\
\hline & & $\begin{array}{l}\text { Design, Data collection, } \\
\text { data analysis, Drafting of } \\
\text { manuscript }\end{array}$ & \\
\hline \multirow[t]{2}{*}{2} & \multirow[t]{2}{*}{ JM } & Corresponding author & \multirow{2}{*}{$\begin{array}{l}\text { Department of Pediatrics, Advanced Pediatrics } \\
\text { Centre, Post Graduate Institute of Medical } \\
\text { Education and Research (PGIMER), Chandigarh, } \\
\text { India -160012. }\end{array}$} \\
\hline & & $\begin{array}{l}\text { Concept, design, data } \\
\text { supervision, critical review } \\
\text { of manuscript and draft } \\
\text { modification }\end{array}$ & \\
\hline 3. & $A B$ & $\begin{array}{l}\text { Data supervision and } \\
\text { review of manuscript }\end{array}$ & $\begin{array}{l}\text { Department of Pediatrics, Advanced Pediatrics } \\
\text { Centre, Post Graduate Institute of Medical } \\
\text { Education and Research (PGIMER), Chandigarh, } \\
\text { India }-160012\end{array}$ \\
\hline 4 & $\mathrm{KN}$ & $\begin{array}{l}\text { Data supervision and } \\
\text { critical review of } \\
\text { manuscript }\end{array}$ & $\begin{array}{l}\text { Department of Pediatrics, Advanced Pediatrics } \\
\text { Centre, Post Graduate Institute of Medical } \\
\text { Education and Research (PGIMER), Chandigarh, } \\
\text { India -160012. }\end{array}$ \\
\hline 5 & BB & $\begin{array}{l}\text { Assisted in field visits and } \\
\text { data collection }\end{array}$ & $\begin{array}{l}\text { Department of Pediatrics, Advanced Pediatrics } \\
\text { Centre, Post Graduate Institute of Medical } \\
\text { Education and Research (PGIMER), Chandigarh, } \\
\text { India }-160012 \text {. }\end{array}$ \\
\hline
\end{tabular}

All authors have read and approved the manuscript

Acknowledgements: None

\section{References}

1. Ratcliffe J. Provision of intensive care for children. BMJ. 1998 May 23;316(7144):1547-8.

2. Newbrander W, Ickx P, Werner R, Mujadidi F. Compliance with referral of sick children: a survey in five districts of Afghanistan. BMC Pediatr. 2012;27;12:46.

3. Loudon I. The principle of referral: the gatekeeping role of the GP. Br J Gen Pract. 2008 Feb 1;58(547):128-30.

4. MD RMK, MD BMDS, MD JSG, PhD NFS MD. Nelson Textbook of Pediatrics, 2-Volume Set. Elsevier Health Sciences; 2015. 5111 p.

5. Santhanam I, Pai M, Kasturi K, Radhamani MPet al. Mortality after admission in the pediatric emergency department: a prospective study from a referral children's hospital in southern India. Pediatr Crit Care Med J 2002 Oct;3(4):358-63. 
6. WHO | IMCl information package [Internet]. WHO. [cited 2019 May 13]. Available from: https://www.who.int/maternal_child_adolescent/documents/chs_cah_98_1a/en/

7. Sankar J, Singh A, Narsaria P, Dev N, Singh P, Dubey Net al. Prehospital transport practices prevalent among patients presenting to the pediatric emergency of a tertiary care hospital. Indian J Crit Care Med 2015;19:474-8.

8. Font F, Quinto L, Masanja H, Nathan R, Ascaso C, Menendez C, et al. Paediatric referrals in rural Tanzania: the Kilombero District Study - a case series. BMC Int Health Hum Rights. 2002 Apr 30;2(1):4.

9. Kloos H. Utilization of selected hospitals, health centres and health stations in central, southern and western Ethiopia. Soc Sci .1990;31(2):101-14.

10. Xiang A, Smith H, Hine P, Mason K, Lanza S, Cave A, et al. Impact of a referral management "gateway" on the quality of referral letters; a retrospective time series cross sectional review. BMC Health Serv Res. 2013;13(1).

11. Langalibalele M, H MPM, P MSW, Ndim, V e J, Benjamin L-M. Quality of General Practitioner Referral Letters to a South African Tertiary Hospital: Determinants of Quality Content and Good Practice. J Public Health Epidemiol. 2011 Nov 30;3(11):482-8.

12. Lachman PI, Stander IA. The referral letter-a problem of communication. South Afr Med J Suid-Afr Tydskr Vir Geneeskd. 1991 Jan 19;79(2):98-100.

13. Xiang A, Smith H, Hine P, Mason K, Lanza S, Cave A, et al. Impact of a referral management "gateway" on the quality of referral letters; a retrospective time series cross sectional review. BMC Health Serv Res. 2013 Aug 14;13:310.

14. Manias E, Geddes F, Watson B, Jones D, Della P. Perspectives of clinical handover processes: a multisite survey across different health professionals. J Clin Nurs. 2016;25(1-2):80-91.

15. Westerman RF, Hull FM, Bezemer PD, Gort G. A study of communication between general practitioners and specialists. Br J Gen Pract. 1990 Nov;40(340):445-9.

\section{Figures}




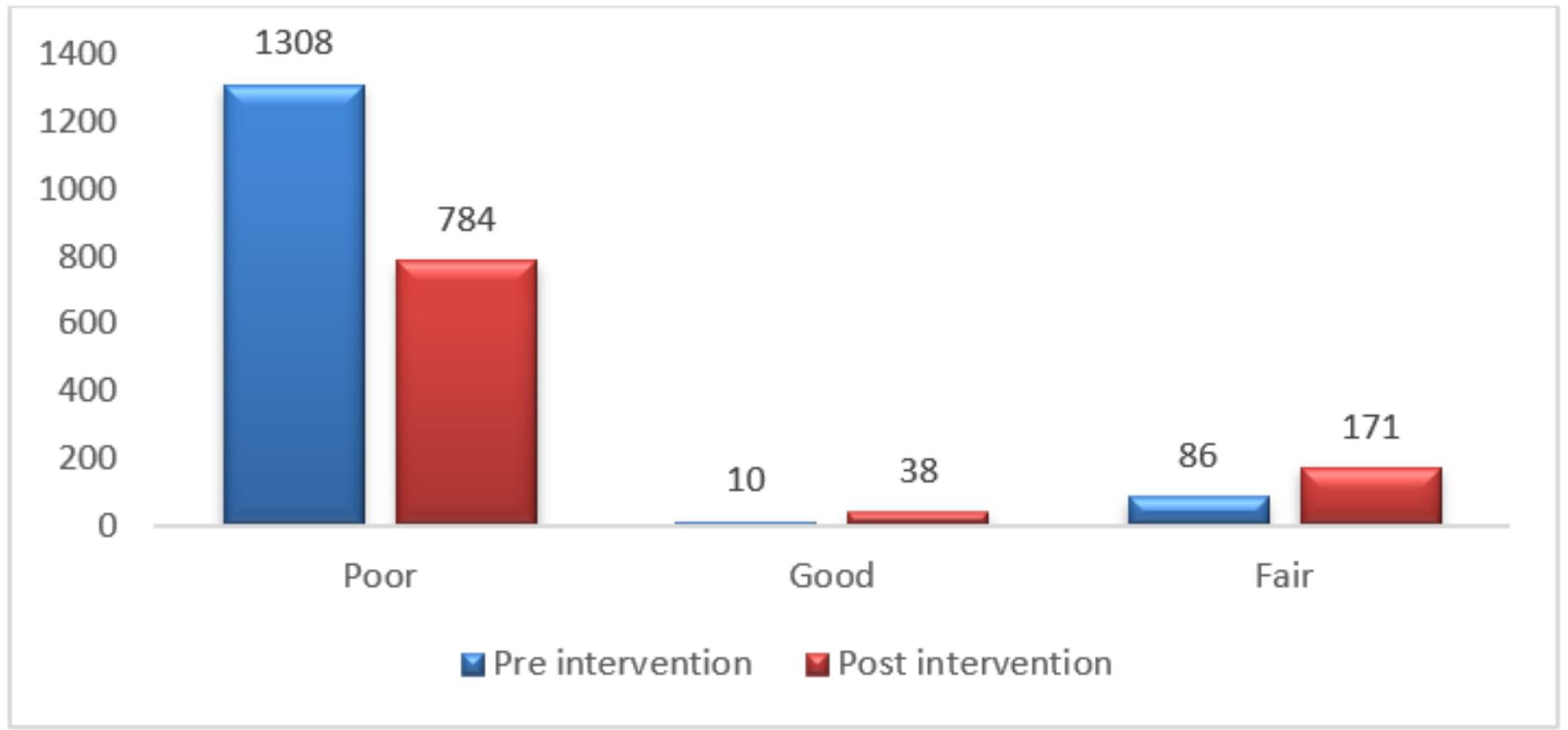

Figure 1

Comparison of quality of referrals ( pre vs postintervention phase ) 